\title{
Metabolic syndrome and associated factors among severely ill psychiatric and non-psychiatric patients: a comparative cross-sectional study in Eastern Ethiopia
}

\author{
Dilnessa Fentie ${ }^{1 *}$, Tariku Derese ${ }^{2}$, Bekele Yazie ${ }^{1}$ and Yibeltal Getachew ${ }^{3}$
}

\begin{abstract}
Background: Metabolic syndrome is a major public health challenge in both developed and developing countries. The burden of this disease is high, even in patients with psychiatric disorders. However, very little is known about the association between metabolic syndrome and psychiatric illness in Ethiopia. Therefore, the aim of this study was to investigate the magnitude of metabolic syndrome and its components among psychiatric clients.

Methods: A comparative cross-sectional study was undertaken between psychiatric patients and age-and sexmatched non-psychiatric controls at the Dilchora referral hospital. The study included 192 study participants (96 psychiatric patients and 96 non- psychiatric controls from general medical and surgical patients). The National Cholesterol Education Program: Adult Treatment Panel III criteria were used to diagnose metabolic syndromes. The data were cleaned and analyzed using the Statistical Package for Social Sciences, Version 21. All intergroup comparisons for continuous data were performed using an independent sample t-test, whereas categorical data were analyzed using the Chi-square test. Logistic regression analysis was used to identify the association between metabolic syndrome and the associated variables.
\end{abstract}

Results: The magnitude of metabolic syndrome among psychiatric patients was 36.5\% (95\%Cl: 27.6, 47.4) compared to non-psychiatric control patients, $21.9 \%(95 \% \mathrm{Cl}: 13.5,30.3), \mathrm{p}=0.02$. The prevalence of MetS components, such as waist circumference (25.0\% vs. 14.3\%), lower-high density lipoprotein level (35.4\% vs. 20.8\%), higher systolic blood pressure (41.7\% vs. $29.2 \%)$ and higher fasting blood glucose ( $40.6 \%$ vs. $18.8 \%)$ showed statistically significant differences between the exposed and non-exposed groups. Age greater than 50 years (AOR: 2.8, Cl: 1.14, 20.0, p<0.05); being female (AOR: 7.4, Cl: 2.0, 27.6, $\mathrm{p}<0.05$ ), being urban residence (AOR: 6.4, Cl: 2.2, 20.6, $\mathrm{p}<0.05$ ), ever alcohol intake (AOR: $5.3, \mathrm{Cl}: 1.3,21.2$ ), being physically inactive (AOR: $3.52, \mathrm{Cl}: 1.1,12.9, \mathrm{p}<0.05$ ) and family history of hypertension (AOR: 2.52, Cl: 1.1, 12.2, $\mathrm{p}<0.05)$ were independent predictors of metabolic syndrome $(\mathrm{p}<0.05)$.

Conclusions: There is a high burden of metabolic syndrome and its components in patients with severe psychiatric disorders. Therefore, screening and mitigation strategies for metabolic syndrome and their components should be implemented in the management of psychiatric disorders.

\footnotetext{
*Correspondence: fagitaabo@gmail.com

1 School of Medicine, College of Medicine and Health Sciences, Dire Dawa University, P.O. Box 1362, Dire Dawa, Ethiopia

Full list of author information is available at the end of the article
}

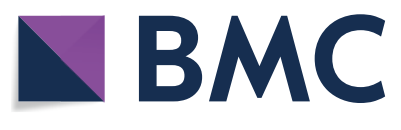

(c) The Author(s) 2021. Open Access This article is licensed under a Creative Commons Attribution 4.0 International License, which permits use, sharing, adaptation, distribution and reproduction in any medium or format, as long as you give appropriate credit to the original author(s) and the source, provide a link to the Creative Commons licence, and indicate if changes were made. The images or other third party material in this article are included in the article's Creative Commons licence, unless indicated otherwise in a credit line to the material. If material is not included in the article's Creative Commons licence and your intended use is not permitted by statutory regulation or exceeds the permitted use, you will need to obtain permission directly from the copyright holder. To view a copy of this licence, visit http://creativecommons.org/licenses/by/4.0/. The Creative Commons Public Domain Dedication waiver (http://creativeco mmons.org/publicdomain/zero/1.0/) applies to the data made available in this article, unless otherwise stated in a credit line to the data. 


\begin{abstract}
Plain language summary
Metabolic syndrome is a risk factor for cardiovascular disease that has public health issues, which places social, economic, and disease conditions in the community within the geographical region of sub-Saharan Africa, including Ethiopia. Patients with psychiatric illness have a 2-threefold risk of morbidity and mortality from metabolic syndrome compared to the general population. Here, we look at range of the possible reasons psychiatric patients have less physical activity due to functional disorders or psychotropic medication, psychological stress, excessive alcohol intake, and inadequate medical care. We assessed the burden of metabolic syndrome and its components among psychiatric patients as compared to non-psychiatric individuals in Eastern Ethiopia for a period of 6 months. There has been an alarming increase in the burden of metabolic syndrome and its components among patients with psychiatric illness. Hence, our results allow readers to aware of the burden of metabolic syndrome and factors involved in the development of the syndrome among psychiatric clients.
\end{abstract}

Keywords: Metabolic syndrome, Dilchora Hospital, Eastern Ethiopia, Psychiatric disorders

\section{Introduction}

Central obesity, hypertension, type 2 diabetes mellitus (T2DM), and atherogenic dyslipidemia are among the cardiometabolic risk factors that make up metabolic syndrome, often known as insulin resistance syndrome [1, 2].Central obesity, leads to an increase in the flow of free fatty acids and cytokine proinflammatory mediators that contribute to the development of insulin resistance [3, 4]. The inflammatory cytokines interleukin- 6 and tumor necrosis factor alpha released from expanded visceral adipose tissue impair insulin signaling due to increased phosphorylation of insulin receptor substrate-1 (IRS-1) $[5,6]$.

Insulin resistance, which is a key underlying feature of type 2 diabetes mellitus, has been shown to be associated with dyslipidemia (hypertriglyceridemia and hypo-high-density lipoprotein cholesterol (HDLc)) and systemic hypertension [7]. Dyslipidemia is defined as raised triglycerides and decreased high- density lipoprotein cholesterol levels. HDL receives triglycerides from very low- density lipoprotein with the activity of the cholesterol ester transport protein, HDL particles are rich in triglycerides, which can be rapidly cleared by hepatic lipase. Insulin resistance reduces the retention of free fatty acids by adipocytes due to the lack of inhibition of insulin by hormone-sensitive lipase, and high rates of triglyceride synthesis $[8,9]$.

Metabolic syndrome is a major public health problem that has been recognized as a global epidemic by the World Health Organization [10, 11]. Metabolic diseases impact roughly $20 \%-25 \%$ of the world's population and are linked to a twofold increase in the risk of death and a threefold increase in the risk of heart attack $[12,13]$ and its prevalence is $2-3$ times higher in people with psychiatric disorders [14-18].

Metabolic syndrome is a major public health challenge in both developed and developing countries due to rapid urbanization, an increasing aging population, sedentary lifestyle, and dietary changes that act together as a web of risk factors which entangles people in it and leads to several non-communicable diseases among psychiatrically ill patients.

In Ethiopia, the burden of MetS has not yet been estimated, especially for patients with psychiatric disorders. Therefore, the aim of our study was to determine the prevalence, and factors associated with MetS among people with psychiatric illnesses attending Dilchora hospital, in Eastern Ethiopia.

\section{Materials and methods Study setting and design}

An institution-based comparative cross-sectional study was conducted among patients with psychiatric disorders and non-psychiatric individuals. The study was conducted at the Dilchora Hospital (DCH) from January 5 to June 10, 2021. Dilchora hospital is located $515 \mathrm{~km}$ away from the capital city, Addis Ababa, Ethiopia. The hospital's psychiatry unit provides service for more than 4500 clients per year, and 1250 clients have registered for a follow-up visit. Monthly patient flow in the clinic ranges from to $390-420$ and weekly patient flow is estimated to be $110-160$.

\section{Population of the study}

Cases/Severe psychiatric disorders/exposed/-established diagnoses of a common psychiatric disorder include schizophrenia, schizoaffective disorder, major depressive disorder, and bipolar disorder [19].

Controls/Non-psychiatric study groups/non-exposed group/were age-and sex-matched individuals, who did not have any psychiatric diagnoses, and who attended outpatient departments for general medical or surgical treatment other than psychiatric disorders, or who had no lifetime diagnosis or treatment for a mental illness. 


\section{Source population}

For cases: All clients attending the $\mathrm{DCH}$, psychiatric clinic for treatment or advice during the study period.

For controls: All clients attending DCH, medical or surgical out patient department for treatment or medical advice during the study period.

\section{Study population}

For cases: All selected clients attending the DCH, psychiatric clinic for treatment or advice during the study period.

For controls: All selected clients attending DCH, medical or surgical out patient department for treatment or medical advice during the study period.

\section{Selection criteria}

Both men and women, aged 18 years and older were included in the study. However, both study groups with a history of pregnancy, previously known heart failure, renal failure, hormonal contraceptive use, and HIV seropositivity were excluded from the study.

\section{Sample size determination}

The sample size was calculated using the formula for a hypothesis test for analytical studies [20]. To calculate the sample size, we considered the overall prevalence of metabolic syndrome among psychiatric patients to be $28.9 \%$ [21] and the prevalence of metabolic disorders among non-psychiatric populations to be $12.5 \%$ [22]. The estimated sample size for two-sample comparison of proportion at $80 \%$ power and $95 \%$ confidence level of certainty, and assuming a $10 \%$ non-response rate, the required sample size was 192 study participants (96 psychiatric patients and 96 non-psychiatric controls).

$$
\begin{aligned}
\mathrm{n}(\text { each group })= & \frac{(\mathrm{r}+1) \times \mathrm{p} * \times(1-\mathrm{p} *)}{\mathrm{r}(\mathrm{p} 1-\mathrm{P} 2)^{2}} \\
& \times(\mathrm{Z} \alpha+\mathrm{Z} \beta)^{2}=87
\end{aligned}
$$

Adding $10 \%$ of $87=9+87=96, \mathrm{n}=$ Minimum sample size for each group, $\mathrm{Z}$ a/2 $=$ critical value at $95 \%$ confidence level of certainty (1.96) (a constant), Z $\beta$ : This depends on power, (the probability of rejecting the null hypothesis when in fact false) for $80 \%$ this is 0.84 , $\mathrm{P} 1=$ Proportions of MetS patients with psychiatric disorder, $28.9 \%=0.289, \mathrm{P} 2=$ Proportion of Mets among nonpsychiatric patients, $12.5 \%=0.125$.

$\mathrm{P}^{*}=$ average percentage between the two groups $=$ $(\mathrm{p} 1+\mathrm{p} 2) / 2=42.3 \% / 2=0.211, \mathrm{q}=1-\mathrm{p}^{*}=1-0.211=0.79$, $\mathrm{d}=$ clinically meaningful difference between the two groups $(\mathrm{p} 1-\mathrm{p} 2)=0.289-0.125=0.174, \mathrm{r}=$ ratio of diseased to non-diseased $=1$, equal number of cases to controls.

\section{Sampling technique}

Exposed study participants were selected consecutively to recruit all 96 severely ill psychiatric patients (diagnosed by psychiatrists or psychiatric clinical officers). After the data were collected from a Single case category, one corresponding age and sex matched non psychiatric controls were selected by convenience sampling.

\section{Operational definitions}

Metabolic syndrome (MetS): is defined according to the modified United States National Cholesterol Education Program, Adult Treatment Panel (NCEP-ATP) III Guideline. Patients had at least three of the following risk features to be categorized under the MetS group: elevated waist circumference (WC) greater than or equal to $102 \mathrm{~cm}$ in men and $88 \mathrm{~cm}$ in women, elevated triglycerides (TG) greater than or equal to $150 \mathrm{mg} / \mathrm{dl}$, reduced high-density lipoprotein-cholesterol, (HDL-C) less than $40 \mathrm{mg} / \mathrm{dl}$ in men and $50 \mathrm{mg} / \mathrm{dl}$ in women, elevated blood pressure greater than or equal to $130 \mathrm{mmHg}$ systolic blood pressure (SBP) or $85 \mathrm{mmHg}$ diastolic blood pressure (DBP), elevated fasting blood glucose (FBG) greater than or equal to $110 \mathrm{mg} / \mathrm{dl}$, and metabolic disorder was diagnosed when $\geq 3$ risk factors were present [23].

A vigorous-intensity activity: which causes a large increase in breathing or heart rate, if continued for at least $75 \mathrm{~min}$ (e.g., running, carrying, or lifting heavy loads, digging, or construction work) per week or engaging in leisure- time exercise at least three times a week for $30 \mathrm{~min}$.

Moderate-intensity activity: which causes a small increase in breathing or heart rate, if continued for at least 150 min (brisk walking or carrying light loads) per week or walking for at least $30 \mathrm{~min}$ per day [24].Adults should perform at least $150 \mathrm{~min}$ of moderate-intensity physical activity or $75 \mathrm{~min}$ of vigorous-intensity physical activity per week, according to the WHO recommendation [25].

Smoking status: The study participants were all smokers (current, current daily, and past smokers), coded as ( $1=$ yes) and non-smoker, coded as $(2=$ no).

Alcohol consumption: The study groups were ever consumers of any alcohol coded as $(1=$ yes $)$ and lifetime abstainer coded as $(2=$ no). The ever- consumer/ consumer of any alcohol represents current alcoholic drinkers (past 30 days) which is coded as $(2=$ no and $1=$ yes) and past alcoholic drinkers (drank in the past 12 months) coded as $(2=$ no and $1=$ Yes $)$.

\section{Data collection method and quality controls}

All study groups were interviewed and blood tests were performed to determine sociodemographic, behavioral 
and clinical variables of the study groups. The questionnaires were adapted from the WHO STEP wise approach recommended for non-communicable disease surveillance. The data were collected by trained psychiatric nurses and laboratory technologists with close supervision of the investigators. The data collectors applied the same procedures to both psychiatric and non-psychiatric clients to collect data.

\section{Biochemical analysis}

About 5-6 $\mathrm{ml}$ of the venous blood sample was collected after an overnight fast (8-12 h) and dispensed into fluoride oxalate tubes and vacutainer plain tubes for separation into plasma and serum, respectively. After clot formation, the blood specimen was centrifuged at 2000 revolution per minute $(\mathrm{rpm})$ for $10 \mathrm{~min}$ within $30 \mathrm{~min}$ of collection and stored at $2-8{ }^{\circ} \mathrm{C}$. Finally, and the serum was separated from the whole blood. Then, the serum was analyzed using an automated clinical chemistry analyzer for total cholesterol, high- density lipoprotein cholesterol, triglycerides and fasting blood sugar.

\section{Data quality control}

Pretest of the data collection tool (questionnaire) was done by pre-testing 5\% of questionnaires at the Goro health center, and necessary corrections were made prior to the actual data collection period. Trained psychiatric nurses and laboratory technologists participated in data collection, blood sample collection, and laboratory diagnosis. Blood samples were collected from all subjects between 8:00 and 12:00 h (a.m.) after 8-12 h overnight fast. The pre-analytical, analytical and post analytical factors that interfere with the results of the biochemical measurements were controlled and maintained by a medical laboratory technologist performing the laboratory analysis. Moreover, commercially prepared quality control samples were used daily prior to running the study samples in order to assess the function of the instrument's, laboratory chemicals, and procedural performances with strict adherence to standard operating procedures. The blood pressure status was measured using a standardized and calibrated sphygmomanometer with appropriate cuff sizes. The apparatus was calibrated daily before data collection.

\section{Data analysis and presentation}

The data were cleaned and then entered into Epi Data 3.1, and then exported to the Statistical Package for Social Sciences (SPSS), Version 21 for statistical analysis. The Chi-square test and Student's t-test were used respectively to compare categorical and continuous variables between the two study groups. Logistic regression analysis was used to analyze factors associated with metabolic syndrome. A bivariable analysis with a p-value $<0.25$ and variables considered medically significant were candidates for multivariable logistic regression analysis. Odds ratios and $95 \%$ confidence intervals (CIs) were calculated to determine the independent risk factors associated with MetS. Data were presented using narrative, figures, and tables from the results of the statistical analysis. Statistical significance was set at $\mathrm{p}<0.05$.

\section{Results}

Socio-demographic characteristics of the study groups

A total of 192 study participants (96 psychiatric and 96 non-psychiatric individuals) were interviewed. The mean age (years) of psychiatric patients was $37.18 \pm 12.59$ whereas, $36.59 \pm 13.56$ for non-psychiatric individuals, which was a statistically insignificant difference between the two groups $(\mathrm{p}=0.754)$. Around $32.2 \%$ of psychiatric patients and $44.8 \%$ of non-psychiatric study participants attended college and above the educational level. The majority of psychiatric study participants were unmarried (51.1\%) and rural dwellers (61.5\%). Moreover, the vast majority of exposed study participants (75\%) were unemployed as compared to their non-exposed counterparts (37.5\%) (Table 1).

\section{The magnitude of metabolic syndrome}

The magnitude of metabolic syndrome among psychiatric exposed patients was $36.5 \%$, whereas it was $21.9 \%$ among non-exposed controls $(\mathrm{p}=0.0026)$. In addition, the components of metabolic disorders among psychiatric exposed patients were more likely to have a broader waist circumference, reduced HDL-C level, higher systolic blood pressure, and higher fasting blood glucose levels compared to the non-psychiatric control clients, whose corresponding burdens were: $25.0 \%$ vs. $14.3 \%$ $(\mathrm{p}=0.01), 35.4 \%$ vs. $20.8 \%(\mathrm{p}=017), 41.7 \%$ vs. $29.2 \%$ $(\mathrm{p}=0.022), 40.6 \%$ vs. However, serum triglycerides and diastolic pressure showed statistically insignificant differences between psychiatric and non-psychiatric patients (Table 2).

\section{Predictors of metabolic syndrome among psychiatric patients}

All variables were entered into a binary logistic regression to select candidate variables. All covariates with a p value of less than 0.25 in the bivariate analysis were included in the multivariable analysis. Hence, bivariate analysis revealed that being female, age of study participants, place of residence, educational status, alcohol consumption, physical inactivity, duration of psychiatric illness, and family history of hypertension were associated with metabolic syndrome at $p$ value $<0.25$. Multivariable analysis showed that age greater than 50 years 
Table 1 Socio- demographic characteristics of the study groups, Eastern Ethiopia, 2021

\begin{tabular}{|c|c|c|c|}
\hline Characteristics & $\begin{array}{l}\text { Psychiatric patients } \\
\text { Number }=96 \\
\text { Number (\%) }\end{array}$ & $\begin{array}{l}\text { Non- } \\
\text { psychiatric } \\
\text { patients } \\
\text { Number =96 } \\
\text { Number (\%) }\end{array}$ & $p$ value \\
\hline Sex & & & $0.561^{* *}$ \\
\hline Male & 55 (57.3\%) & $56(58.3 \%)$ & \\
\hline Female & $41(42.7 \%)$ & $40(41.7 \%)$ & \\
\hline Age (mean $\pm S D)$ & $37.18 \pm 12.59$ & $36.59 \pm 13.56$ & $0.754^{* *}$ \\
\hline Educational status & & & $0.076^{*}$ \\
\hline No formal education & 45 (46.9\%) & $26(27.1 \%)$ & \\
\hline Primary education & $3(3.1 \%)$ & $6(6.3 \%)$ & \\
\hline Secondary education & $17(17.7 \%)$ & $21(21.9 \%)$ & \\
\hline College \& above & 31 (32.2\%) & 43 (44.8\%) & \\
\hline Marital status & & & $0.743 *$ \\
\hline Single/unmarried & 35 (36.5\%) & $33(34.4 \%)$ & \\
\hline Married & $12(12.5 \%)$ & $33(34.4 \%)$ & \\
\hline $\begin{array}{l}\text { Divorced/separated/ } \\
\text { died }\end{array}$ & $12(12.5 \%)$ & $13(13.5 \%)$ & \\
\hline Residence & & & $0.009 *$ \\
\hline Rural & $59(61.5 \%)$ & 41 (42.7\%) & \\
\hline Urban & $37(38.5 \%)$ & $55(57.3 \%)$ & \\
\hline Employment & & & $0.061 *$ \\
\hline Unemployed & $72(75.0 \%)$ & $36(37.5 \%)$ & \\
\hline Employed & $24(25.0 \%)$ & $60(62.5 \%)$ & \\
\hline Ever smoked & & & $0.86^{*}$ \\
\hline No & 79 (82.3\%) & $82(85.4 \%)$ & \\
\hline Yes & $17(17.7 \%)$ & & \\
\hline Ever Alcohol Intake & & & $0.401^{*}$ \\
\hline No & 70 (72.9\%) & 75 (78.1\%) & \\
\hline Yes & $26(27.1 \%)$ & $21(21.9 \%)$ & \\
\hline $\begin{array}{l}\text { Regular physical } \\
\text { activity }\end{array}$ & & & $0.521 *$ \\
\hline Yes & 39 (40.6\%) & $29(30.2 \%)$ & \\
\hline No & $57(59.4 \%)$ & 67 (69.8\%) & \\
\hline $\begin{array}{l}\text { Family history of hyper- } \\
\text { tension }\end{array}$ & & & $0.082^{*}$ \\
\hline Yes & $36(37.5 \%)$ & $13(13.5 \%)$ & \\
\hline No & 69 (71.9\%) & 83 (86.5\%) & \\
\hline $\begin{array}{l}\text { Family history of } \\
\text { diabetes }\end{array}$ & & & $0.013^{*}$ \\
\hline Yes & $27(28.1 \%)$ & $13(13.5 \%)$ & \\
\hline No & $68(70.8 \%)$ & $83(86.5 \%)$ & \\
\hline
\end{tabular}

SD Standard deviation

**Independent sample T test, *Pearson's chi-square test

(AOR: 2.8, CI: 1.14, 20.0, $\mathrm{p}<0.05$ ); being female study participants (AOR: 7.4, CI: 2.0, 27.6, $\mathrm{p}<0.05$ ), being urban residence (AOR: 6.4, CI: 2.2, 20.6, $\mathrm{p}<0.05$ ), alcohol intake (AOR: $5.3, \mathrm{CI}: 1.3,21.2)$, being physically inactive (AOR: $3.8, \mathrm{CI}: 1.1,12.9, \mathrm{p}<0.05$ ) and family history of hypertension (AOR: 3.8, CI:1.1, 12.2, p<0.05)were independent predictors of MetS among psychiatric patients $(\mathrm{p}<0.05)$ (Table 3).

\section{Discussion}

Ethiopia is a developing sub-Saharan country; like other developing countries, it is going through an epidemiological transition from communicable to non-communicable diseases in general. This comparative cross-sectional study identified a high prevalence of metabolic syndrome among severely ill psychiatric patients compared to nonpsychiatric individuals, which was $35.6 \%$ and $21.9 \%$, respectively. This finding was consistent with the studies reported in Qatar [26], South Africa [27], and Egypt [28] which found a higher magnitude of metabolic syndrome among psychiatric-exposed patients compared with nonpsychiatric study participants. High burden of metabolic syndrome among psychiatric clients could be due to psychiatric patients having less physical activity due to functional disorders, psychological stress, excessive alcohol intake, excessive smoking, and inadequate medical care have been implicated [7-9].

The overall prevalence of metabolic syndrome among psychiatric patients in the current study was $(35.6 \%)$ comparable with different studies: $28.9 \%$ at Jimma University Medical Center, Ethiopia [21], 34.74\% in Kashmir [29] and 43.6\% in Palestine [30]. However, the prevalence estimated in the present study was much higher than in studies conducted in Hawassa, 24.5\% [31], 23.51\% in Uganda [15], and 24.3\% in Brazil [32]. The possible difference could be due to differences in types or generation of antipsychotic agents used by the patients (in our study, most of the patients used first-generation antipsychotics at the time of study), period of study, patients' lifestyle, patterns of psychiatric illness (in our study, patients with severe psychiatric disorder were considered), duration of psychiatric illness, and sociocultural differences [33-35].

In our study, most of the metabolic syndrome components were highly frequent in patients with psychiatric disorders compared to non-psychiatric controls. The magnitude of waist circumference was significantly higher in patients with severe psychiatric illness than in non-psychiatric controls, which was $25 \%$ vs. $14.3 \%$, $\mathrm{p}=0.03$. The magnitude of fasting blood glucose was significantly higher among patients with severe psychiatric disorders (40.6\%) compared to the non-psychiatric controls $(18.8 \%), \mathrm{p}=0.001$. The magnitude of reduced high density lipoprotein dyslipidemia was significantly higher among severely ill psychiatric patients (35.4\%) than among non-psychiatric controls (20.8\%). In addition, the magnitude of systolic blood pressure was higher in severely ill psychiatric patients (41.7\%) than in non-psychiatric controls (29.2\%), $\mathrm{p}=0.022$. This was comparable 
Table 2 Metabolic disorder and its components among the study groups, Eastern Ethiopia, 2021

\begin{tabular}{|c|c|c|c|c|c|}
\hline Characteristics & $\begin{array}{l}\text { Psychiatric patients } \\
\text { (exposed) }\end{array}$ & $95 \% \mathrm{Cl}$ & Non-psychiatric & $95 \% \mathrm{Cl}$ & P value \\
\hline Overall magnitude MetS & $35(36.5 \%)$ & $(27.6,47.4)$ & $21(21.9 \%)$ & $(13.5,30.3)$ & 0.026 \\
\hline $\begin{array}{l}\text { Increased waist circumference (males }>102 \mathrm{~cm} \text {, } \\
\text { females }>88 \mathrm{~cm} \text { ) }\end{array}$ & $24(25.0 \%)$ & $(17.2,35.4)$ & $10(14.3 \%)$ & $(7.8,23.0)$ & 0.010 \\
\hline High systolic blood pressure ( $\geq 130$ mm Hg) & $40(41.7 \%)$ & $(17.2,31.7)$ & $28(29.2 \%)$ & $(22.4,38.5)$ & 0.022 \\
\hline High diastolic blood pressure ( $\geq 85 \mathrm{mmHg}$ ) & $28(29.2 \%)$ & $(20.8,39.1)$ & $18(18.8 \%)$ & $(13.5,27.6)$ & 0.091 \\
\hline Raised triglycerides (> $150 \mathrm{mg} / \mathrm{dl}$ ) & $37(38.5 \%)$ & $(29.2,48.5)$ & $26(27.1 \%)$ & $(19.8,39.1)$ & 0.270 \\
\hline High fasting plasma glucose ( $\geq 110 \mathrm{mg} / \mathrm{dl})$ & $39(40.6 \%)$ & $(21.7,40.1)$ & $18(18.8 \%)$ & $(10.4,25.0)$ & 0.001 \\
\hline $\begin{array}{l}\text { Low HDL levels } \\
\text { (males }<40 \text { mg/dl, females }<50 \text { mg/dl) }\end{array}$ & $34(35.4 \%)$ & $(24.0,42.8)$ & $20(20.8 \%)$ & $(19.2,34.4)$ & 0.017 \\
\hline
\end{tabular}

Statically significant $(\mathrm{p}<0.05)$, HDL high density lipoprotein, MetS Metabolic syndrome

Table 3 Factors associated with metabolic syndrome among psychiatric patients at Dilchora Hospital psychiatric center, Eastern Ethiopia, 2021

\begin{tabular}{|c|c|c|c|c|c|}
\hline \multirow[t]{2}{*}{ Parameter } & \multirow[t]{2}{*}{ Category } & \multicolumn{2}{|l|}{ MetS } & \multirow[t]{2}{*}{ COR $(95 \% \mathrm{Cl})$} & \multirow[t]{2}{*}{ AOR $(95 \% \mathrm{Cl})$} \\
\hline & & Yes & No & & \\
\hline \multirow[t]{4}{*}{ Age (years) } & $18-30$ & $6(20.0 \%)$ & $24(80 \%) 1$ & 1 & 1 \\
\hline & $31-40$ & 7 (26.9\%) & $9(73.1 \%)$ & $0.97(0.6-1.5)$ & $0.33(0.06,2.28)$ \\
\hline & $41-50$ & $10(47.6 \%)$ & $11(52.4 \%)$ & $0.57(0.3-0.89)$ & $1.1(0.18,7.24)$ \\
\hline & $>50$ & $12(63.2 \%)$ & $7(36.8 \%)$ & $6.8(1.88-24.9)$ & $2.8(1.04,20.0)^{*}$ \\
\hline \multirow[t]{2}{*}{ Gender } & Male & $13(25 \%)$ & 39 (75.0\%) & 1 & 1 \\
\hline & Female & $22(50.0 \%)$ & $22(50.0 \%)$ & $3(1.26,17.10)$ & $7.4(2.0,27.6)^{*}$ \\
\hline \multirow[t]{4}{*}{ Education } & Uneducated & $23(51.1 \%)$ & $22(48.9 \%)$ & $3(1.11,8.1)$ & $5.3(0.1 .0,25.5)$ \\
\hline & Primary & $1(33.3 \%)$ & $2(66.7 \%)$ & $1.4(0.11,18.07)$ & $4.7(0.11,18)$ \\
\hline & Secondary & $3(17.6 \%)$ & $66(0.14,2.7)$ & $14(82.4 \%)$ & $2.3(0.31,17.3)$ \\
\hline & College and above & $8(25.8 \%)$ & $23(74.2 \%)$ & 1 & 1 \\
\hline \multirow[t]{2}{*}{ Residency } & Rural & $11(18.6 \%)$ & $48(81.4 \%)$ & 1 & 1 \\
\hline & Urban & $24(64.9 \%)$ & $13(35.1 \%)$ & $8(3.14,20.6)$ & $6.4(2.2,20.6)^{*}$ \\
\hline \multirow[t]{2}{*}{ Ever smoked } & No & $26(32.9 \%)$ & $53(67.1 \%)$ & 1 & 1 \\
\hline & Yes & $9(52.9 \%)$ & $8(47.1 \%)$ & $2.29(0.79,6.6)$ & $2.3(0.36,17.8)$ \\
\hline \multirow[t]{2}{*}{ Ever taken alcohol } & No & $19(27.1 \%)$ & $51(72.9 \%)$ & 1 & 1 \\
\hline & Yes & $16(61.5 \%)$ & $10(38.5 \%)$ & $4.29(1.66,11.10)$ & $5.3(1.3,21.2)^{*}$ \\
\hline \multirow[t]{2}{*}{ Regular physical activity } & Yes & $8(20.5 \%)$ & 31 (79.5\%) & 1 & 1 \\
\hline & No & $27(47.4 \%)$ & $30(52.6 \%)$ & $3.48(1.36,8.88)$ & $3.8(1.1,12.9)^{*}$ \\
\hline \multirow[t]{2}{*}{ Family history of hypertension } & Yes & $18(50.0 \%)$ & $18(50.0 \%)$ & $2.52(1.06,5.98)$ & $3.8(1.1,12.2)^{*}$ \\
\hline & No & $17(28.3 \%)$ & $43(71.7 \%)$ & 1 & 1 \\
\hline \multirow[t]{3}{*}{ Duration of mental illness (years) } & $<5$ & $6(24.0 \%)$ & $19(76.0 \%)$ & 1 & 1 \\
\hline & $5-10$ & $5(22.7 \%)$ & $17(77.3 \%)$ & $0.931(0.24,3.612)$ & $0.45(0.04,4.2)$ \\
\hline & $>10$ & $24(49.0 \%)$ & $25(51.0 \%)$ & $3.04(1.03,8.9)$ & $0.58(0.10,3.18)$ \\
\hline
\end{tabular}

MetS metabolic syndrome, COR crude odds ratio, AOR adjusted odds ratio

$*=p<0.05$

to the study conducted in Egypt in 2017; almost all components of metabolic syndrome were significantly higher in psychiatric patients than in non-psychiatric individuals [26, 36-42].

Higher odds of having metabolic syndrome were found in female subjects, the advanced age group, subjects who were urban residents, physically inactive individuals, and subjects who were alcohol consumers. Participants over the age of 50 were found to be significantly more likely to have MetS (AOR: 2.8, CI: 1.14, 20.0, P 0.05). Muscle, fat, and other tissues may become less sensitive to insulin as we age, resulting in dysglycemia and dyslipidemia 
[43]. And also, as age increases, arteries get stiffer, so blood pressure goes up due to loss of elastin fibers and accumulation of stiffer collagen fibers in the media of large arteries [44]. This finding is similar to a previous study reported in Kashmir [29] and Jimma, Ethiopia [21]. In contrast, a study conducted in Ghana discovered that age ( $>53$ years) was statistically insignificant in the development of metabolic syndrome [45].We speculate that it could be due to variations in socioeconomic factors and health seeking behaviors among the two study populations.

In addition, the present study revealed that participants of female sex were at higher risk of developing metabolic syndrome than those of male participants (AOR: 7.4, CI: 2.0, 27.6, $\mathrm{p}<0.05)$. This result is consistent with the studies conducted in Kashmir [29], South Africa [46], South West Ethiopis [21] and Southern-Ethiopia [31]. Possible explanations for this gender disparity include differences in physiology, level of physical activity, and psychological factors between the male and female sexes.

Urban residency was found to be an important risk factor for metabolic syndrome (AOR: 6.4, CI: 2.2, 20.6, $\mathrm{p}<0.05)$. This could be explained by the fact that urban residency associated with physical inactivity and consumption of calorie-rich diets contributed to the pathogenesis of metabolic syndrome. This finding is consistent with a study conducted in Poland [47] and Bangladesh [48].

The present study also showed a significant relationship between alcohol consumption and the development of MetS (AOR: 5.3, CI: 1.3, 21.2). The possible reason might be associated with excessive caloric intake through alcoholic consumption leads to adipocyte hypertrophy and increases visceral adipose tissue. Adipose tissue possibly secretes many cytokines and reactive oxygen radicals, thus promoting inflammation and insulin resistance syndrome $[44,49,50]$. This finding was in line with the studies conducted in Southern Ethiopia [31] and Venezuela [51] ever alcohol intake was significantly associated with metabolic syndrome. However, this finding was in contrast with the study conducted in Jimma that found alcohol intake was not associated with metabolic syndrome [21].We speculate the difference could be due to the time variation, the socio-economic and cultural factors observed between the study participants.

In the present study, participants with low physical activity were at a higher risk of developing metabolic syndrome (AOR: 3.52, CI: 1.1, 12.9, $\mathrm{p}<0.05$ ). This finding was comparable with similar studies in Taiwan in 2016 [52] and China [53]. Conversely, there was an inconsistent report from Uganda in 2017 that said the level of physical activity was not associated with the development of metabolic syndrome [26].The possible justification could be partly due to information relying on self-reporting data, which is prone to information bias, sociodemographic variation among the two study groups. The current study also showed that the risk of developing MetS was 2.5 times greater than having a family history of hypertension. This finding is in line with the reports of previous studies in Sri Lanka in 2015 [54] and Ghana in 2018 [55]. The possible reason might be associated with blood relatives, who tend to have many of the same genes that can predispose a person to MetS, or relatives may also share some of the same habits such as diet, exercise, and substance use that can affect risk [56].

\section{Strengths and limitations of the study}

As per the knowledge of the researchers, this study is one of the first analytical comparative studies to assess the magnitude of metabolic disorder and its associated factors among patients with severe psychiatric disorder and non-psychiatric controls in Ethiopia. As a result, the project investigated the prevalence of metabolic disorders in patients with psychiatric disorders, who are less frequently studied for these disorders than age- and gender-matched non-psychiatric patients who are thought to be representative of similar settings. We compared our results with those of age-and sex-matched "non-psychiatric" controls. This study investigated several variables, which can also influence the burden of metabolic disorders in patients with a psychiatric disorder. In addition, it was assured that biochemical analysis was done in clinical chemistry laboratory machines that passed the laboratory quality management system and were accredited by the Ethiopian National Accreditation Office by following the requirements of ISO: 2020 for technical competency. Our data was supplemented by clinical measurements with biochemical analysis that might raise the reliability/accuracy of the estimate or diagnosis of metabolic disorder.

Our study had some limitations. It was conducted in one health facility, and findings from the study may not be generalizable beyond the population of patients attending Dilchora referral hospital. The study may have been subjected to social desirability/acceptability bias from study participants wanting to provide socially desirable responses to questions about risky lifestyles such as smoking and alcohol consumption. We did not assess the dietary habits of the study participants, yet these are important determinants of metabolic disorders.

\section{Conclusions}

In Dilchora Hospital, Eastern Ethiopia, metabolic syndrome and its components are highly prevalent among psychiatric patients. Early detection and appropriate intervention are mandatory among patients with 
advanced age, female sex, urban residency, alcohol consumers, physically inactive individuals, and family history of hypertension. Frequent clinical and biochemical monitoring should, therefore, form part of care in patients with psychiatric disorders on follow-up visits. In addition, routine assessment of sociodemographic, behavioral, and biological risk factors should be institutionalized to address the burden of metabolic syndrome. Furthermore, future prospective research should be implemented to identify the relationship between psychiatric illnesses and metabolic syndrome.

\section{Abbreviations \\ BMI: Body mass index; DCRH: Dilchora Referral Hospital; DBP: Diastolic blood pressure; MetS: Metabolic syndrome; HDL-c: High Density Lipoprotein cho- lesterol; NCEP/ATP3: National Cholesterol Education Adult Treatment Panel III; SBP: Systolic blood pressure.}

\section{Acknowledgements}

We are grateful to Dire Dawa University for its support and funding. We would like to thank all study participants, Dilchora psychiatric and regional laboratory staff for their contributions that have made this study possible.

\section{Authors' contributions}

DF designed and conducted the main research project and write up. TD involved in data interpretation, analysis, and write- up. BY was involved in data analysis and interpretation. YG involved in preparing the study designed and manuscript drafting. All authors read and approved the final manuscript.

\section{Funding}

This project was funded by research and community engagement office, Dire Dawa University (Grant Nos.120, 213 birr).

\section{Availability of data and materials}

The data used to support the findings of this research are available on request from the corresponding author.

\section{Declarations}

\section{Ethics approval and consent to participate}

Ethical clearance was obtained from the Institutional Review Board (IRB) of Dire Dawa University, college of medicine and health sciences (protocol no. 300/55//2021). The regional health office and hospital higher officials agreed to the carrying out the study at Dilchora Hospital. A letter of cooperation was obtained from Dire Dawa regional health office before the study commenced. A written informed consent was obtained from all study participants at the time of the study. Permission was asked to respondents and none of them was forced to participate in this study. Any identifiable issue was eliminated to ascertain confidentiality. All laboratory analysis was performed free of charge, and all participants who have metabolic disorder were referred to a respective physician for further evaluation.

\section{Consent for publication}

Not applicable.

\section{Competing interests}

All the authors declared no conflict of interest regarding the publication of this paper.

\section{Author details}

${ }^{1}$ School of Medicine, College of Medicine and Health Sciences, Dire Dawa University, P.O. Box 1362, Dire Dawa, Ethiopia. ${ }^{2}$ Department of Public Health, College of Medicine and Health Sciences, Dire Dawa University, Dire Dawa, Ethiopia. ${ }^{3}$ Department of Psychiatry, College of Medicine and Health Sciences, Dire Dawa University, Dire Dawa, Ethiopia.
Received: 16 August 2021 Accepted: 28 October 2021

Published online: 10 November 2021

\section{References}

1. Steckhan N, Hohmann CD, et al. Effects of different dietary approaches on inflammatory markers in patients with metabolic syndrome: a systematic review and meta-analysis. Rev Assoc Med Bras. 2016;63(1):338-48.

2. Kao T-W, Huang C-C. Recent Progress in Metabolic Syndrome Research and Therapeutics. Int J Mol Sci. 2021;22:6862. https://doi.org/10.3390/ ijms22136862.

3. Heymsfield SB, Wadden TA. Mechanisms, pathophysiology, and management of obesity. N Engl J Med. 2017;376:254-66. https://doi.org/10.1056/ NEJMra1514009.

4. Al-Suwaidi J. Is there an increased cardiovascular risk in metabolically healthy obese individuals? Lessons from the HUNT (Nord-Trøndelag Health) study. Global Cardiol Sci Pract. 2014. https://doi.org/10.5339/ gcsp.2014.24

5. Rochlani Y, Pothineni NV, Kovelamudi S. Metabolic syndrome : pathophysiology, management, and modulation by natural compounds. Ther Adv Cardiovasc Dis. 2017;11:215-25. https://doi.org/10.1177/1753944717 711379.

6. Aquilante CL, Pharm D, Griend JP Vande, Pharm D, Cardiology AQ, Parra D, et al. Metabolic syndrome. Pharmacotherapy Self-Assessment Program, 6th Edition. 2019;

7. Scheen AJ. Pathophysiology of type 2 diabetes. Acta Clinica Belgica. 2003:58(6):335-41.

8. Kolovou G, Cardiac O, Anagnostopoulou KK. Pathophysiology of dyslipidemia in the metabolic syndrome. Postgrad Med J. 2014;81:358-66. https://doi.org/10.12997/jla.2015.4.2.93.

9. Potenza MVMJ. How do elevated triglycerides and low hdl-cholesterol affect inflammation and atherothrombosis? Fr K Welty. 2013;15(9):560-77.

10. Association AD. Diagnosis and classificationof diabetes melitus. Diabetes Care. 2010:6(33):62-9.

11. Moreira MC, Izabella S, de Jesus-Pinto A, et al. Prevalence of the metabolic syndrome in patients with coronary heart disease, cerebrovascular disease, peripheral arterial disease or abdominal aortic aneurysm. Atherosclerosis. 2015;6(173):363-9.

12. Holt R, Abdelrahman T, Hirsch M, et al. The prevalence of undiagnosed metabolic abnormalities in people with serious mental illnesses. J Psychopharmacol. 2016;24:867-73. https://doi.org/10.1177/0269881109 102788 (Epub 2016 Mar 20).

13. Mogre V, Salifu ZS, Abedandi R. Prevalence, components and associated demographic and lifestyle factors of the metabolic syndrome. J Diabetes Metab Disord. 2014;2:1-7. https://doi.org/10.1186/2251-6581-13-80.

14. WHO. Burden of mental disorders, at department of mental health and substance dependence. Geneva: Switzerland; 2019. p. 1226.

15. Agaba DC, Migisha R, Namayanja R, Katamba G, Lugobe HM, Aheisibwe H, Twesigomwe G, Ashaba S. Prevalence and associated factors of metabolic syndrome among patients with severe mental illness attending a Tertiary Hospital in Southwest Uganda. Biomed Res Int. 2019:2019(3):339-47. https://doi.org/10.1155/2019/1096201.

16. Alosaimi FD, Abalhassan M, Alhaddad B, Alzain N, Fallata E, Alhabbad A, et al. Mortality in mental disorders and global disease burden implications: a systematic review and meta-analysis. Gen Hosp Psychiatry. 2015:72:334-41. https://doi.org/10.1001/jamapsychiatry.2015.2502.

17. Ringen PA, Engh JA, Birkenaes AB, et al. Increased mortality in schizophrenia due to cardiovascular disease - a non-systematic review of epidemiology, possible causes, and interventions. Front Psychiatry. 2014;5:137. https://doi.org/10.3389/fpsy.2014.00137.

18. Gouda HN, Charlson F, Sorsdahl K, Ahmadzada S, Ferrari AJ, Erskine H, et al. Articles Burden of non-communicable diseases in sub-Saharan Africa, 1990-2017: results from the Global Burden of Disease Study. Lancet Glob Heal. 2017;7(10):e1375-87. https://doi.org/10.1016/S2214109X(19)30374-2.

19. APA. American Psychiatric Association. DSM-5. APA DSM. 2013;5:631417881 1-888-357-PSYCH (1-888-357-7924).

20. Charan J, Biswas T. How to calculate sample size for different study design in medical research? Indian J Psychol Med. 2013;35(2):121-6. https://doi. org/10.4103/0253-7176.116232. 
21. Sintayehu A, Bekele S, Tolessa D, Cheneke W. Metabolic syndrome and associated factors among psychiatric patients in Jimma University Specialized Hospital, South West Ethiopia. Diabetes Metab Syndr Clin Res Rev. 2018;12(5):753-60. https://doi.org/10.1016/j.dsx.2018.04.037.

22. Gelaye B, Girma B, Lemma S, Berhane Y. Prevalence of metabolic syndrome among working adults in Ethiopia prevalence of metabolic syndrome among working adults in Ethiopia. Int J Hypertens. 2011;10:1.

23. Gelaye B, Girma B, Lemma S, Berhane Y. Prevalence of metabolic syndrome among working adults in Ethiopia prevalence of metabolic syndrome among working adults in Ethiopia. Int J Hypertens. 2011. https:// doi.org/10.4061/2011/193719.

24. Atpiii- N. Updated third report of the National Cholesterol Education Program (NCEP) expert panel on detection, evaluation, and treatment high blood pressure choleterol in adults. JAMA. 2005;285(55):2486-97.

25. WHO. WHO Guidelines on physical activity and sedentary behaviour for children and adolescents, adults and older adults for consultation only. 2020:1-34.

26. Kumar A, Narayanaswamy JCV, et al. Prevalence of metabolic syndrome and its clinical correlates among patients with severe psychiatric disorder. Asian J Psychiatr. 2017;56(4):109-14. https://doi.org/10.1016/j.ajp.2017.01. 020 (Epub 2017 Jan 27).

27. Saloojee S, Burns JK, Motala AA. Metabolic syndrome in south african patients with severe mental illness : prevalence and associated risk factors. PLoS One. 2016. https://doi.org/10.1371/journal.pone.0149209.

28. Mousa FA, Dessoki HH, El SM, Ezzat AA, Soltan MR. Metabolic syndrome in psychiatric patients (comparative study). Egypt J Psychiatry. 2017. https://doi.org/10.4103/ejpsy.ejpsy_24_17.

29. Hussain T, Margoob MA, Shoib S, Shafat M, Chandel RK. Prevalence of metabolic syndrome among psychiatric in patients: a hospital based study from Kashmir. J Clin Diagnostic Res. 2017;11(6):2015-8. https://doi. org/10.7860/JCDR/2017/25801.10011.

30. Sweileh WM, Saed HZ, Dalal SA, Ibwini S, et al. Prevalence of metabolic syndrome among patients with Schizophrenia in Palestine. BMC Psychiatry. 2012;12:235. https://doi.org/10.1186/1471-244X-12-235.

31. Teshome T, Kassa DH, Hirigo AT. Prevalence and associated factors of metabolic syndrome among patients with severe mental illness at Hawassa Southern-Ethiopia. Dovepress. 2020;13:569-79. https://doi.org/ 10.2147/DMSO.S235379.

32. Moreira FP, Jansen K, Cardoso TD, Mondin TC, Magalhaes PV, Kapczinski F, Souza LD, da Silva RA, Oses JP, Wiener CD. Metabolic syndrome and psychiatric disorders: a population-based study. Braz J Psychiatry. 2018:41:38-43. https://doi.org/10.1590/1516-4446-2017-2328.

33. Brenda WH, Penninx SM. Metabolic syndrome in psychiatric patients: overview, mechanisms, and implications. World Psychiatry. 2018;13(2):153-60. https://doi.org/10.31887/DCNS.2018.20.1/bpenninx.

34. Correll CU, Mak DS, Mailey DS, Farrelly E, Rajagopalan K, Loebel A. Cardiometabolic comorbidities, readmission, and costs in schizophrenia and bipolar disorder : a real - world analysis. Ann Gen Psychiatry. 2017. https:// doi.org/10.1186/s12991-017-0133-7.

35. Ringen PA, Faerden A, Antonsen B, Falk RS, et al. Cardiometabolic risk factors in people with severe psychiatic disorders. Br J Psychiatry. 2013;183:534-9. https://doi.org/10.1007/978-981-287-206-7_15.

36. Huang MC, Lu ML, Tsai CJ, Chen PY, Chiu CC, Jian DL, Lin KM, Chen CH. Prevalence of metabolic syndrome among patients with schizophrenia or schizoaffective disorder in Taiwan. Acta Psychiatrica Scandinavica. 2009;120(4):274-80. https://doi.org/10.3889/aph.2019.286.

37. Mitchell AJ, Vancampfort DSK. Prevalence of metabolic syndrome and metabolic abnormalities in schizophrenia and related disorders-a systematic review and meta-analysis. Schizophr Bull. 2013;2(39):306-18. https:// doi.org/10.1093/schbul/sbr148.

38. Meyer JM, Goff DC, Nasrallah HA, Davis SMS. Prevalence of the metabolic syndrome in patients with schizophrenia: baseline results from the Clinical Antipsychotic Trials of Intervention Effectiveness (CATIE) schizophrenia trial and comparison with national estimates from NHANES III. Schizophrenia Res. 2016;80(1):19-32. https://doi.org/10.1016/j.schres.

39. Aguilar $M$, et al. Prevalence of the metabolic syndrome in the United States. JAMA. 2015. https://doi.org/10.1001/jama.2015.4260.

40. Woldeyohannes HO, Soczynska JKMA, et al. The rate of metabolic syndrome in euthymic New Canadian individuals with bipolar disorder. Adv Ter. 2018. https://doi.org/10.1007/s12325-010-0072-z.
41. Ghuloum S, Mahfoud Z, Yehya AA, et al. The prevalence of metabolic syndrome in patients receiving antipsychotics in Arab Pensula: a cross sectional comparative study. BMC Psychiatry. 2018;18(81):19-24. https:// doi.org/10.1186/s12888-018-1662-6.

42. Al-Hamaq AO, Dafeeah E. A two fold risk of metabolic syndrome in a sample of patients with schizophrenia: Do consanguinity and family history increase risk? Diabetes \& Metabolic Syndrome. Clin Res. 2014;6(4):4-8. https://doi.org/10.1016/j.dsx.2014.10.003 (Epub 2014 Nov 14).

43. Cerezo C, Segura JPM, et al. Guidelines updates in the treatment of obesity or metabolic syndrome and hypertension. Curr Hypertens Rep. 2013;15:196-203. https://doi.org/10.1007/s11906-013-0337-4.

44. Chowdhury I, Points K. Alcohol and dyslipidemia: alcohol, nutrition, and health consequences. Nutr Health. 2013. https://doi.org/10.1001/jama. 2013.284427

45. Agyemang-yeboah F, Ackon B, Eghan J, Annani-akollor ME, Togbe E, Donkor $S$, et al. Evaluation of metabolic syndrome and its associated risk factors: a descriptive cross-sectional study at the Komfo Anokye Teaching Hospital, Kumasi Ghana. Biomed Res Int. 2019;2:8. https://doi.org/10. 1155/2019/4562904.

46. Mohapi M, Rheeder P. The prevalence of metabolic syndrome and its associated factors in long-term patients in a specialist psychiatric hospital in South Africa. Afr J Psychiatry. 2013. https://doi.org/10.4314/ajpsy.v16i6. 53.

47. Nowicki GJ, Ślusarska B, Naylor K, et al. The relationship between the metabolic syndrome and the place of residence in the local community on the example of the janów Lubelski District in Eastern Poland. Dove Press. 2021;14(May):2041-56. https://doi.org/10.2147/DMSO.S301639.

48. Billah S, Johan M. Metabolic syndrome in urban and rural communities of Bangladesh. J Int Vol Heal Sci. 2018;2(2):71-7. https://doi.org/10.31344/ ijhhs.v2i2.29.

49. Jung Y, Kang L, Kim H, Park H, Hwang H, Park K. Relationship between Marital Status and Metabolic Syndrome in Korean Middle- Aged Women : Korea. Korean J Fam Med. 2018;39:307-12. https://doi.org/10.4082/kjfm. 17.0020 (Epub 2018 Jul 6).

50. Vaccaro O, Masulli M. The concept of metabolic syndrome : contribution of visceral fat accumulation and its molecular mechanism. J Atheroscler Thromb. 2012;18:629-39. https://doi.org/10.5551/jat.7922.

51. Bermúdez V, Martínez MS, Chávez-Castillo M, Olivar LC, et al. Relationship between alcohol consumption and components of the metabolic syndrome in adult population from Maracaibo City Venezuela. Adv Prev Med. 2015;2015:13. https://doi.org/10.1155/2015/352547 (Epub 2015 Dec 8).

52. Yang CY, Lo SC, Peng YC. Prevalence and predictors of metabolic syndrome in people with schizophrenia in inpatient rehabilitation wards. Biol Res Nurs. 2016;18(5):558-66. https://doi.org/10.1177/1099800416653184 (Epub 2016 Jun 5)

53. Xiao J, Shen C, Chu MJ, Gao YX, Xu GF, Huang JP. Physical activity and sedentary behavior associated with components of metabolic syndrome among people in Rural China. PLoS ONE. 2016;11(1):1-15. https://doi.org/ 10.1371/journal.pone.0147062.

54. Ranasinghe P, Cooray DN, Jayawardena R, Katulanda P. The influence of family history of Hypertension on disease prevalence and associated metabolic risk factors among Sri Lankan adults. BMC Public Health. 2015;15(19):1-9.

55. Yeboah K, Dodam KK, Affrim PK, Adu-Gyamfi L, Bado AR, Mensah RN, Adjei AB, Gyan B. Metabolic syndrome and parental history of cardiovascular disease in young adults in urban Ghana. BMC Public Health. 2018;18(1):1-8.

56. Delacroix S, Chokka RG, Worthley SG. Hypertension: Pathophysiology and treatment. J Neurol Neurophysiol. 2014;5:6. https://doi.org/10.4172/21559562.1000250

\section{Publisher's Note}

Springer Nature remains neutral with regard to jurisdictional claims in published maps and institutional affiliations. 